\title{
SCIENTIFIC SESSION SUMMARIES
}

\section{SUNDAY}

JS1.

Human and Experimental Neurobiology of Epilepsy

J.A. WADA (Co-chair) (Canada); P. LOISEAU (Co-chair) (France); M. SATO (Japan) and J. NOEBELS (U.S.A.).

This symposium explores aspects of controversy in partial onset epilepsy and examines new development in our understanding of generalized onset epilepsy from both clinical and experimental perspectives.

The first part examines clinical relevance of EEG mirror focus formation in partial onset epilepsy through examination of kindling model of sccondary epileptogencsis in four different primate species and suggests necessity of expanding our conceptual horizon beyond the clinical seizure as the most visible symptom of epilepsy. This will be followed by a critical clinical assessment of psychosis developing in medically refractory partial onset epilepsy. Etiological discussion for epileptic psychosis will be based on the finding of pharmacological and neurochemical consequences of repeated secondarily generalized seizure in kindling model of epilepsy.

The second part deals with the new development in our understanding of generalized onset epilepsy with spike and wave discharge as a model. The initial part will examine genetic heterogeneity through several animal models of absence epilepsy to define general principles regarding the heredity of this abnormal cortical bisynchronization trait. This will be complemented by a comprehensive evaluation of petit mal phenotype regarding its diversity as seen in clinical practise.

JS2.

\section{ALS}

N. LEIGH (Co-chair) (U.K.); P. FAWCETT (Co-chair) (U.K); L.P. ROWLAND (U.S.A.); D. FIGLEWICZ (Canada) and A. EISEN (Canada).

Within the last year there have been important advances in our understanding of the pathogenesis of ALS. The role of these findings emphasizes the probable importance of endogenous and exogenous neurotoxins, but the factors determining the relatively selective involvement of the upper and lower motor neurones are still unknown. New understanding of the pharmacology and physiology of the motor systems will be important in interpreting the new findings in molecular neurobiology, and if new therapeutic agents prove effective, attention will focus on early diagnosis and prevention of disability.

Dr. Nigel Leigh will discuss recent functional brain imaging, pathological and biochemical studies in ALS. These are clarifying the nature of the cortical and cerebral lesions in ALS. This knowledge will be important in understanding the pathogenesis of the disease process. Functional imaging may have a role in early diagnosis.

Dr. Lewis P. Rowland will review the spectrum of advances in understanding of the pathogenesis of ALS and other motor neurone disorders, including autoimmunity, excitotoxicity, and involvement of free radicals.

Dr. Denise Figlewicz will describe results of recent genetic linkage studics, the detection and significance of mutations in the gene coding for superoxide dismutase 1 , and oudine the future stratcgy of neurogenetic research in ALS and other familial motor neurone disorders. The implications of the SOD 1 gene mutations for sporadic ALS will be discussed.

Dr. Peter Fawcett will discuss the physiology of the motor unit, in particular the contribution of single fibre and macro-EMG techniques.

Dr. Andrew Eisen will review the pathophysiology of upper motor neurone involvement, outline methods of evaluating this clinically and electrophysiologically, and consider the relationship between upper and lower motor neurones in the pathogenic process.

\section{MONDAY}

T1.

Molecular Genetics of Neurological Disease

A.E. HARDING (Co-chair) (U.K.); E. ANDERMANN (Co-chair) (Canada); G. ROULEAU (Canada); P.F. CHANCE (U.S.A.); K. JOHNSON (U.K.); R. BARCHI (U.S.A.); S.B. PRUSINER (U.S.A.); R. ELSTON (U.S.A.); G. EBERS (Canada) and B. SEIZINGER (U.S.A.).

This symposium will illustrate the increasing applications of molecular genetics to research and clinical practice in neurological disorders. Rouleau will review basic principles and techniques, with particular application to disorders of the motor neuron. Prusiner will discuss prion disease, and Chance recent advances in inherited neuropathies related to mutations of a peripheral myelin protein gene. Johnson will describe three disorders related to unstable DNA sequences, myotonic dystrophy, bulbospinal neuronopathy and the fragile-X syndrome. Barchi will conclude the session on single gene disorders by discussing disorders associated with sodium channel gene defects. The genetic approach to common ncurological disorders is complex, and will be described by Elston. This theme will be developed in relation to multiple sclerosis (Ebcrs) and epilcpsy (Andermann). Seizinger will review the molecular genetics of both inherited neurological tumour syndromes and gliomas. Harding will conclude by describing the applications of molecular genetics to neurological practice.

S1.

\section{Botulinum Toxin Treatment in Neurology}

M.F. BRIN (Co-chair) (U.S.A.); Z. PIRTOSEK (Co-chair) (U.K.); M. HALLETT (U.S.A.); E. TOLOSA (Spain); I. LORENTZ (Australia); R. KAJI (Japan) and J. JANKOVIC (U.S.A.).

Local injections of botulinum toxin (BTX) into excessively contracting muscles have resulted in substantial improvement in symptoms and quality of life for patients with focal and segmental dystonia. BTX treatment has helped many patients with tremor and spasticity. This symposium will survey the clinical disorders, and review the chemistry and pharmacology of BTX, and discuss utilization in blepharospasm, hemifacial spasm, torticollis (cervical dystonia), spasmodic dysphonia, oromandibular dystonia and other jaw spasms, limb dystonias (including writer's and occupational cramps), spasticity and essential and parkinsonian tremors. Demonstration videotapes of the technique and response to therapy will be shown. 
S2.

\section{Sports Neurology}

B.D. JORDAN (Co-chair) (U.S.A.); A. ASBURY (Co-chair) (U.S.A.); R. CANTU (U.S.A.); S. DIAMOND (U.S.A); M. HALLETT (U.S.A); D. BENNETT (U.S.A.) and H. GREER III (U.S.A.).

Basic and selected concepts of Sports Neurology will be discussed. Topics will include head and neck injuries in sports, epilepsy and the athlete, the evaluation and management of headaches in the athlete, and entrapment neuropathies in sports. There will also be a discussion of the neurologic complications of scuba diving and boxing.

S3.

\section{Neuro-Epidemiology}

L.T. KURLAND (Co-chair) (U.S.A.); A. PORTERA-SANCHEZ (Co-chair) (Spain); C. TANNER (U.S.A.); N. BHARUCHA (India); A. KORCZYN (Israel); W. ROCCA (Italy); C. ESTEBAN-SANTILLAN (Guam) and S. WARING (Guam).

Papers have been sclected to illustrate methodological aspects of population-based studies that provide reliable data on incidence, geographic distribution, outcome, and risk factors for neurological disorders. The symposium also commemorates the 25 th anniversary of the initiation of the neuroepidemiology research center at Mayo Clinic, which utilizes the records-linkage system developed for the population of Rochester and Olmsted County, Minnesota. The chairman will review the history of that system, its remarkable productivity, and its liberal policy which enables students and scientists from around the world to utilize this resource for appropriate research. Tanner will report on Parkinson's disease covering 50 years in the Olmsted County population, with comparisons of earlier studies in China. She will also discuss the prospective evaluation of an MPTP-exposed cohort. Bharucha will describe surveys for various neurological diseases in the Parsi population of Bombay, India, and will provide comparison data with results in Olmsted County. Korczyn will describe the emerging discipline of epidemiologic genetics in neurology, with emphasis on the dementias; he will also provide a comparison of rates for selected neurological diseases that have been studied in Israel. Rocca will provide a comparison of the rates and risk factors for Alzheimer's disease in a recent European nulticenter project, and these, too, will be compared with the results in Olmsted County. Esteban and Waring will review the continuing research in the Western Pacific foci on ALS and parkinsonismdementia complex, emphasizing the recent population surveys on Guam and nearby islands in the Marianas. Clinical features and pathological correlations of gaze palsy, Guam retinopathy, and the loss of odor identification will be presented.

\section{S4.}

\section{Tropical Neurology}

J.S. CHOPRA (Co-chair) (India); G. ROMAN (Co-chair) (U.S.A.); N. HUNT (Australia); A. VEJJAJIVA (Thailand) and P.R.M. de BITTENCOURT (Brazil).

Almost all the tropical countries in the world are either underdeveloped or developing countries. Low socio-economic status, unhygienic environments, climatic conditions and low per capita health expenditures play a major role in the prevalence of a number of tropical neurological diseases. Some of the problems which are devastating and some with high prevalence rate are discussed.

Protein energy malnutrition (PEM) is a classical byproduct of poverty and continues to be a source of concern to a large segment of the world population. The developing nervous system is specifically vulnerable to the onslaught of PEM. Peripheral nerve, muscle and CNS especially the neuropsychological functions are affected in a lasting manner. Clinical signs and symptoms supported by electrophysiological and histopathological observations both in humans and experimental model of rhesus monkey support the effect of PEM on the above mentioned areas of the nervous system.

Despite intensive investigations there is still controversy about the nature of the pathological processes in cerebral malaria due to plasmodium falciporum in human beings. Three murine models, the fatal, resolving and non-cerebral models have given the opportunity to study in detail the pathogenesis of cerebral malaria. However, this study has been extended on the retinal whole mount preparation to study the central nervous changes. This has allowed the observation of whole segments of mictovessels and cell to cell interactions that occur during immunopathological process. It has been shown that microglia and astrocytes are playing some part in the pathogenesis of murine cerebral malaria.

New developments in the laboratory diagnosis of tuberculous meningitis (TBM) have been made to overcome the low yield by direct smear and culture of the causative organism from CSF. Detection of tuberculostearic acid by mass spectrometry, determination of adenosine deaminase activity and various immunologic techniques to detect antigen and antibody in CSF have been reported. Recently, highly promising rapid diagnostic testing by polymerase chain reaction have been applied and their use in human immunodeficiency virus cases with TBM is a real challenge for physicians.

The age adjusted prevalence of epilepsy in tropics where some $25 \%$ of the world population live is presumed to be 10 per 1000 inhabitants, twice that of Western countries. The aetiology of epilepsy reflects the local social, cultural and economic environments. Infection leading to epilepsy include acute, subacute and chronic bacterial, viral and parasitic diseases. Trauma and hypoxia may be the commonest causes of tropical epilepsy. Operating alone or together between conception and adult life, these factors underlie the increased prevalence of epilepsy in the tropics.

The other highlight will be the discussion on differential diagnosis of acute flaccid paralysis in children as seen in the tropics.

S5.

\section{Diagnostic Ultrasound in Neurology}

J.W. NORRIS (Co-chair) (Canada); D. RUSSELL (Co-chair) (Norway); M.G. HENNERICI (Germany); M.P. SPENCER (U.S.A.); C.H. TEGELER (U.S.A.) and C. BISHOP (U.K.).

Increasing sophistication of ultrasound technology is one of the hallmarks of progress in this "decade of the brain". Colour coded Doppler and increased clarity of B-mode imaging are providing superior imaging to angiography in many cases, and are non-invasive. Insonation of the intracranial vasculature is a valuable method of monitoring surgical procedures and diagnosing cerebral embolism. Prediction of future advances in neurosonology will be discussed. 
S6.

\section{Neuro-Ophthalmology}

J.A. SHARPE (Co-chair) (Canada); R. DAROFF (Co-chair) (U.S.A.); J.C. HORTON (U.S.A.); C. PIERROT-DESEILLIGNY (France); V. HENN (Switzerland); J.J. CORBETT (U.S.A.) and A. NEETANS (Bclgium).

This symposium reviews new and classic concepts of the cortical representation of vision (Horton) and cerebral hemispheric regulation of smooth pursuit and saccades (Pierrot-Deseilligny). Brainstem mechanisms of gaze control are illustrated by experimental chemical lesions and unit recording studies in monkeys and by examples of supranuclear ophthalmoplegia in patients (Henn). Saccadic oscillations and intrusions that disrupt fixation by taking the eyes off their target are dyskinesias that provide diagnostic signs of brain disease; they are distinguished from nystagmus. Selected ocular oscillations are demonstrated for their diagnostic value (Sharpe). Optic neuritis is discussed in light of the multi-centre treatment trial with corticosteroids and its possible implications for the management of multiple sclerosis (Corbett). An introduction to quantitative perimetry emphasizes its role relative to confrontation technique and kinetic visual field examination in neurological diagnosis (Nectens). These topics will cover advances in neuro-ophthalmology for both novice and seasoned neurologists while keeping the needs of practitioners at the forefront. Syllabi are provided and a discussion (Daroff) with audience participation concludes the session.

S7.

\section{The Neurology of HIV Infections}

R.T. JOHNSON (Co-chair) (U.S.A.); A. VEJJAJIVA (Co-chair) (Thailand); P. PORTEGIES (The Netherlands); S. LIPTON (U.S.A.); P. KENNEDY (U.K.) and M. TARDIEU (France).

This symposium will update the epidemiology, clinical manifestation, diagnosis, treatment, and pathogenetic mechanisms of HIV infections of the central nervous system. Since the last World Congress, where AIDS was a main theme, HIV infections have continued to spread and intensify with particularly startling burgeoning numbers of infections in Asia. The neurological manifestations have been generally the same in different geographic areas and in different risk groups with exception of the much more rapid disease seen in children which will be reviewed by Dr. Tardieu. The improved treatment of primary HIV disease as well as better treatment of opportunistic infections is now available and will be reviewed by Dr. Portegies. Since infected cells in the nervous system are predominantly, if not exclusively, macrophage and microglia, the cognitive changes, the vacuolar myelopathy, and the axonal degeneration of peripheral nerves are difficult to explain. A variety of indirect mechanisms of disturbed neuronal function will be reviewed by $\mathrm{Dr}$. Lipton. Insights into the pathogenesis of HIV-associated neurological diseases from studies of animal lentivirus will be reviewed by Dr. Kennedy.

S8.

Clinical Neurophysiology of the Motor System

J. KIMURA (Co-chair) (Japan); A. EISEN (Co-chair) (Canada); J. ROTHWELL (U.K.); H.-J. FREUND (Germany) and J. DAUBE (U.S.A.).

This symposium consists of four 50-minute sessions dealing with (1) charting cortical connections with magnetic stimulation, (2) functional imaging and imaging function (3) the facts and fallacies of motor conduction block and (4) getting the most out of needle electromyography. All presentation will focus on recent advances in clinical neurophysiology of the motor system. In general, each session is designed for clinical neurologists interested in new developments in motor physiology as well as those who, trained in electrodiagnostic medicine, wish to update the knowledge in special procedures. We will review current approaches to common diseases of the motor system in an overview designed for neurologists in practice or in training. The presentation will emphasize the physiologic basis of various techniques, their relative importance in the differential diagnosis and possible contribution in problem solving in the clinical domain. We will provide an ample opportunity for discussion with members of the faculty at the conclusion of the session.

\section{TUESDAY}

\section{T2.}

\section{Recent Advances in Headache}

M.A. MOSKOWITZ (Co-chair) (U.S.A.); F.C. ROSE (Co-chair) (U.K.); J. LANCE (Australia); J. OLESEN (Denmark); J. FOZARD (Switzerland); P.J. GOADSBY (Australia); B. SESSLE (Canada); J. EDMEADS (Canada); K.M. WELCH (U.S.A.); T. STEINER (U.K.) and M. FERRARI (The Netherlands).

Traditionally viewed as a vascular disorder, eleven intemational experts from seven countries will debate the evidence regarding the relative importance of meningeal blood vessels, trigeminovascular fibers and the brain proper to migraine pathophysiology and treatment. To begin, Jes Olsesen will consider the topical issues and unsolved research problems circa 1993, John Fozard will then review recent knowledge of receptor pharmacology with particular attention to the possible role of $5-\mathrm{HT}_{1 \mathrm{C}}$ and $5-\mathrm{HT}_{1 \mathrm{D}}$ receptor subtypes to onset and treatment. Michael A. Moskowitz will describe the importance of inhibitory sensory receptors expressed on trigeminovascular fibers to migraine treatment and will review the data showing that the brain can be an important initiator of trigeminovascular activation. Peter J. Goadsby will consider the importance of central pathways to the pain, associated symptoms of migraine, and migraine pharmacology. After lunch, Barry Sessle will examine the neurophysiological basis for pain referral and pain spread and describe the neuroplastic responses within brain stem which follow inflammation or injury within deep and superficial facial structures. The impact of these and other discoveries will be considered in several clinical sessions as well. John Edmeads will define the clinical problems circa 1993 with particular attention to strengths and weakness of existing migraine nosology and rational basis for choosing between therapeutic options. Some answers to these questions may come from advances in imaging and related technologies as will be described by $\mathrm{K}$. Michael Welch. Timothy Steiner will then provide guidelines and assess clinical trials in migraine. Michel Ferrari will review the clinical experience with the serotonin agonist sumatriptan and its potential application to unravel pathophysiology in man.

S9.

Dementia: The Clinician's Dilemma

K.L. BICK (Co-chair) (U.S.A); D. MCLACHLAN (Co-chair) (Canada); L. AMADUCCI (Italy); L. BERG (U.S.A.); J.-M. ORGOGOZO (France); V. CHANDRA (India) and $\mathrm{K}$. BEYREUTHER (Germany).

One consequence of the unprecedented graying of the world population is the dramatic rise in the numbers of persons at risk for 
dementia. Amaducci will discuss the diagnostic algorithms used when confronted with a patient with signs of dementia. Berg will elaborate on the limitations of prognostic factors and of the methods used for measuring the course of disease. Orgogozo will present current approaches to management of cognitive and behavioural symptoms in demented patients. Chandra will address the impact of dementia in developing countries and the confounding aspects of polypharmacy and unconventional medications as well as cultural influences on settings for care and caregivers. Beyreuther will consider the role of amyloid B-A4 protein in Alzheimer's disease dementia and discuss possible strategies for presymptomatic interventions that eventuate from the molecular biological approach to the amyloid forming processes.

\section{S10.}

\section{Recent Advances in the Study of Cerebrospinal Fluid}

J.P. ANTEL (Co-chair) (Canada); A. LOWENTHAL (Co-chair) (Belgium); J. WHITAKER (U.S.A.); H. LINK (Sweden); D. HINTON (U.S.A.) and R. ROOS (U.S.A.).

Amongst "readily" accessible fluid compartments in humans, the cercbrospinal fluid (CSF) represents the one which interacts most closely with the tissue components of the central nervous system (CNS). Analysis of the cellular and soluble constituents of the CSF has become an established means to enhance clinical diagnosis and understanding of disease mechanisms in a wide array of human neurologic disorders. Advances in cellular and molecular biologic techniques provide an opportunity to analyze CSF constituents in ever more precise details, by-passing the practical limitations imposed by sample-size available, numbers of cells present, concentration of specific molecules, and handling or storage problems. This symposium will present up-dated information regarding how newly available methodologies can be applied to the study of CSF obtained from patients with infectious, immunologic, neoplastic, and degenerative neurologic disorders and how such information may further enhance both our knowledge regarding disease pathogenesis and diagnostic accuracy. These new opportunities need be considered in the context of how advances in other diagnostics modalities, particularly neuroimaging, influence the clinicians' decision to perform CSF analyses as part of a diagnostic assessment or as a means whereby to monitor disease progression or responses to therapy.

\section{S11.}

\section{Peripheral Neuropathies}

P.K. THOMAS (Co-chair) (U.K.); A. OHNISHI (Co-chair) (Japan); K. FISCHBECK (U.S.A.); F. VAN DER MECHE (The Netherland); J. McARTHUR (U.S.A.) and G. SAID (France).

Peripheral ncuropathics continue to be an active area in terms of identifying new syndromes, in elucidating disease mechanisms and in the introduction of new therapies. In this symposium, Fischbeck will discuss the major progress that had been made on the molecular genetics of inherited neuropathies, Van der Meché will review recent advances in the treatment of inflammatory neuropathies and Thomas will discuss current concepts as to the causation and treatment of diabetic neuropathy. McArthur will delineate the various neuropathies that are related to retroviral infections and Said will review the clinical manifestations, investigation and therapy of neuropathies caused by vasculitis.
S12.

\section{Consciousness}

J.E. DESMEDT (Co-chair) (Belgium); P. HALÀSZ (Co-chair) (Hungary); T. TSUBOKAWA (Japan); F. COHADON (France) and F. PLUM (U.S.A.)

Consciousness is now becoming a manageable problem in terms of brain mechanisms. The conscious function of the brain is shared by mammals and should be viewed in the perspective of Darwinian evolution. It first appeared in simple forms and provided selection advantage for resolving unforeseen behavioral alternatives that cannot be preprogrammed. It was progressively sophisticated along with brain circuits and later culminated with acquisition of language. Transient "binding" of distinct sets of cortical neurons by 40 Herz electrical oscillations may help elucidate brain conscious mechanisms (Desmedt). Global anomalies of consciousness include coma, vegetative state and advanced dementia. Some patients with persistent vegetative state can recover consciousness through chronic electrical stimulation in intralaminar thalamus or reticular formation (Cohadon, Tsubokawa) and challenging problems are raised in conjunction with the mechanisms of progressive re-structuring of the conscious function after head injury with vegetative state. Another set of problems is related to patients with focal unconsciousness associated with damage to parieto-temporal cortex (Plum). Major challenges involving the conscious function of the brain are to be met in clinical neurology and the neurosciences.

\section{S13.}

\section{The Developing Brain}

V. CAVINESS (Chair) (U.S.A.); P. HUNT (U.S.A.); P. EVRARD (Belgium); G. INNOCENTI (Switzerland) and P. FILIPEK (U.S.A.).

The vertebrate nervous system is unrivaled among all organ systems for the variety of its cellular components and in the complexity of the interrelationships and interactions governing the behavior of these elements. The DEVELOPING BRAIN will provide an overview of the principal cellular events through which the mammalian nervous system emerges in early life. The Symposium will direct an eye both to normal and abnormal developmental outcome. Cytogenesis (Caviness), at the outset of histogenesis, is a primary determinant of cell number and diversity. The proliferative populations are "mapped" into broad regions by the primordial action of master (homeotic) genes which coordinately switch on and off extended sets of genes governing cellular and regional specificities (Hunt). Postmitotic neurons undertake extended migratory journeys from their place of origin to their ultimate destinations where they contribute to the pattemed nuclear and cortical arrangements of the mature nervous system (Evrard). Migrations completed, the young neurons elaborate the dendritic and axonal processes and through these engage in the networks that will support neural operations (Innocenti). There follows an extended period of growth and differentiation of both neuronal and glial elements during which the central nervous system acquires its characteristic size and shape (Filipek).

\section{S14.}

\section{Neurobiology of Alzheimer's Disease}

R.N. ROSENBERG (Co-chair) (U.S.A.); P.A. RIEKKINEN (Cochair) (Finland); R. TERRY (U.S.A.); P. ST. GEORGE-HYSLOP (Canada); S. SORBI (Italy) and C. MASTERS (Australia).

This session will emphasize basic science considerations for the pathogenesis of Alzheimer's disease. Morphological, biochemical 
and molecular genetic topics will be covered in depth. Terry et al. have emphasized the importance of synapse loss to explain dementia of AD and will be reviewed in detail. St. George-Hyslop will discuss gene mutations responsible for inherited $A D$ including those described on chromosomes 14q, 21q, 19q and the amyloid precursor protein mutations. Sorbi will discuss his work related to reductions in specific activities of the glycolytic rate-limiting enzymes, hexokinase, phosphofructokinase and transketolase. Masters will review the molecular biology of paired helical filament adnormalities and amyloid polymerization. Rosenberg will review the recently described pathways for amyloid precursor protein processing which may be involved in $\mathrm{AD}$ and present the view for a causal role for amyloid in the pathogenesis of $\mathrm{AD}$.

\section{S15.}

\section{ALS and Related Disorders}

S.H. APPEL (Co-chair) (U.S.A.); M. BEN HAMIDA (Co-chair) (Tunisia); M. SWASH (U.K.); T. SIDDIQUE (U.S.A.); K. ZERRES (Germany) and T. MUNSAT (U.S.A.).

ALS is a relentlessly progressive neurodegenerative disorder that compromises upper and lower motoneurons and culminates in respiratory impairment and death. Although the classical syndrome was originally felt to be confined to the motor system, recent studies demonstrate cases which involve frontal and temporal cortical and subcortical pathways and alter mentation. The etiology and pathogenesis of sporadic ALS is presently unclear. Evidence of decreased spinal cord glutamate and decreased glutamate transport implicates ligand gated calcium channels, but does not define the initiating event. Studies in ALS focusing on autoimmunity demonstrate the presence of antibodies against voltage-gated calcium channels which increase calcium entry into motoneuron cell lines and cause cell death, and may thereby contribute to our understanding of both ctiology and pathogenesis. Evidence from familial ALS demonstrates a genetic defect in superoxide dismutase which could lead to increased free radical damage and cell death. Studies of the gene defect in spinal muscular atrophy should shed further light on whether mechanisms other than increased intracellular calcium and free radical damage are responsible for the selective vulnerability of motoneurons in these disorders. Finally neurotrophic factors are exciting new potential therapies which enhance repair of motoneurons and, at least in vitro, protect against calcium and free radical mediate damage.

\section{S16.}

\section{New Uses of Computers in Neurology}

S.S. STENSAAS (Chair) (U.S.A.); E. MEYER (Canada); M.J. LINCOLN (U.S.A.); C.R. SKINNER (Canada) and J. BORMANIS (Canada).

The symposium will show a variety of programs and platforms being used for neurology, functional imaging and education. Programs used to simulate, animate, present patient video and link hypertext as well as PET, MRI and CT imaging will be demonstrated.

\section{WEDNESDAY}

T3.

\section{Neural Degeneration and Regeneration}

R.J. RIOPELLE (Co-chair) (Canada); K. POECK (Co-chair) (Austria); M. JOHNSTON (U.S.A.); R. BUNGE (U.S.A.); H.-J. FREUND (Germany); R. STEIN (Canada); W. MOBLEY (U.S.A.); F. GAGE (U.S.A.); A. BJÖKLUND (Sweden) and O. LINDVALL (Sweden).

Current and projected estimates of the social and economic impacts of neurological diseases have prompted initiatives in a number of countries focused on mechanisms of neural insult and degeneration, and innovative approaches to foster regeneration and functional recovery. This symposium assembles a panel of neuroscientists to address emerging developments in neural degeneration and regeneration. M. Johnston (USA) will present observations on aspects of developmental brain insult, focusing of excitatory amino acid neurotoxicity, and the role of calcium in neuronal injury. Based upon new insights derived from clinical/pathological correlates of injury to the cervical spinal cord in man, R. Bunge (USA) will discuss implications for prospective therapy of the acute and chronic injury. To emphasize that nervous system healing and functional repair is feasible, $\mathrm{H}$. Freund (Germany) will review observations on spontaneous functional recovery following focal brain injury, while R. Stein (Canada) will focus attention on the recovery of function after regeneration stops. Growth factors for neurons promote survival and permit neurons to express their differentiated functions. $W$. Mobley (USA) will discuss neurotrophic factors in the normal and diseased nervous system, highlighting prospects for novel therapies. F. Gage (USA) will extend this topic to a discussion of somatic gene transfer in support of regeneration in the nervous systcm, and his presentation will introduce the area of neural transplantation in neurodegenerative disease. A. Björklund (Sweden) will provide the rationale for neural transplantation and its experimental basis, and will highlight its clinical perspectives by a discussion of neural transplantation in Huntington disease. O. Lindvall (Sweden) will then present observations on human neural transplantation in Parkinson disease.

\section{S17.}

\section{Ischemic Stroke: Molecular Concepts and Rational Therapy}

W.-D. HEISS (Co-chair) (Germany); J.P. MOHR (Co-chair) (U.S.A.); K.-A. HOSSMAN (Germany); M. GINSBERG (U.S.A.); M. TOMITA (Japan) and L. CANDELISE (Italy).

Experimental evidence collected recently stresses the importance of biochemical-molecular mechanisms for the development of ischemic cell damage. This symposium will attempt to present a synopsis of these new findings with respect to their clinical relevance. It has been well demonstrated that functional and morphological integrity of tissue are dependent of the maintenance of flow above a defined threshold. Likewise, many substrates involved in cell metabolism follow similar threshold relationships. Disturbances in flow initiate deleterious biochemical cascades which proceed in a independent repetitive manner leading to cell death; these include disturbances in extra- and intracellular ionic equilibrium, the formation and liberation of noxious molecules as well as early gene expression. The mediators released aggravate the pathologic state by damaging vascular endothelium which in turn acts to alter blood cells as well as possibly promote platelet adherence and thrombus formation. Some of these pathopysiologic states during the early stages of stroke can be visualized using functional neuroimaging 
techniques such as PET or MRS. As a result, it has been possible to demonstrate the continued existence of compromised viable tissue in and around the area of ischemia. Such findings stress the importance of early and targeted treatment whether it be within the rather short time window available for reestablishing or improving blood flow or the possibly somewhat longer window for the intervention with biochemical changes. Both therapeutic principles must be combined and initiated early after an ischemic attack in order to salvage tissue and to improve stroke outcome.

\section{S18.}

\section{Neurological Aspects of Pain}

J. BOIVIE (Chair) (Sweden); Z. WIESENFELD-HALLIN (Sweden); K.M. FOLEY (U.S.A.); R. TASKER (Canada) and M. MAX (U.S.A.).

Pain is common in patients with diseases in peripheral and central nervous system. Neuropathic pain appears in many guises; it can be excruciating pain with bizarre character covering large parts of the body, or it can have a trivial character and be restricted to a relatively small area, for instance as aching pain in one of the hands. The diagnosis is often difficult and requires knowledge about the clinical features of the various neuropathic pain conditions.

No single treatment is effective for all neuropathic pain. Therefore it is often necessary to test several of the treatment modes before the best treatment is found. The most commonly used treatments are blockades, electrical stimulations of peripheral and central nervous structures, antidepressants and antiepileptic drugs.

Recent work on experimental models of peripheral and central neurogenic pain has provided new insights into the mechanisms of neuropathic pain. These will be reviewed in the symposium, which will also include surveys of the clinical aspects of neuropathic pain in malignancy and of central pain. The results of stimulations of CNS structures and of pharmacologic treatments will be summarized.

\section{S19.}

\section{History of Neurology (CHARCOT SYMPOSIUM)}

K.L. TYLER (Co-chair) (U.S.A.); M. FARDEAU (Co-chair) (France); F.C. ROSE (U.K.); B. BRAIS (Canada); E.G. JONES (U.S.A.); R.R. YOUNG (U.S.A.) and S. ASHWAL (U.S.A.).

This symposium on the history of neurology is being held on the centennial anniversary of Charçot's death. The symposium will begin with a discussion of the early development (pre-1500) of European neurology (F.C. Rose), followed by a study of Charçot and his contributions (B. Brais, M. Fardeau). Subsequent topics will include selective reviews of the historical development of such fundamental themes in neurology as cerebral localization (K.L. Tyler), the neuron doctrine (E.G. Jones), and the neurophysiological foundations of modem clinical neurology (R.R. Young). The symposium will conclude with a discussion of the development of pediatric neurology as an independent subspecialty ( $S$. Ashwal).

S20.

\section{Inflammatory Myopathies}

G. SERRATRICE (Co-chair) (France); H. SUGITA (Co-chair) (Japan); M. DALAKAS (U.S.A.); Y. SHAPIRA (Israel); R. HOHLFELD (Germany); V. ASKANAS (U.S.A.) and F. MASTAGLIA (Australia).

Inflammatory myopathies (IM) represent a heterogeneous group of disorders comprising a number of entities, such as polymyositis
(PM), dermatomyositis (DM) and inclusion body myositis (IBM). They occur at any age from infancy to late adulthood, but juvenile DM is distinct from adult one, has an underlying vasculitic pathology. Dalakas will overview the clinical aspect of IM in adult, while Shapira that in childhood. Hohlfeld will discuss on the pathomechanism of LM using various T-cell markers. Askanas will deal with the immunochemical studies of ubiquitin and B-amyloid protein in IBM in connection with its pathogenesis. Mastaglia will review the recent advances in the treatment of IM.

S21.

\section{Neuro-Immunology}

O. ABRAMSKY (Co-chair) (Israel); P. DUQUETTE (Co-chair) (Canada); T. TABIRA (Japan); J. POLLARD (Australia); J. NEWSOM-DAVIS (U.K.); R. LISAK (U.S.A.) and H. WEINER (U.S.A.).

In this symposium, the clinical and laboratory diagnosis, immunopathogenic mechanisms and immunotherapy of immunemediated neurological diseases, will be presented. Tabira will present the spectrum of the clinical and experimental diseases and their related target antigens in cortical, motor neuron, paraneoplastic, autonomic, demyelinating and neuromuscular diseases. Pollard will concentrate on immune-mediated PNS disorders such as GuillainBarré syndrome, chronic inflammatory polyneuropathy, vasculitis, and paraproteinemic neuropathies and their related experimental autoimmune models and antigens. Newsom-Davis will give an overview on the neuromuscular junction diseases myasthenia gravis, Lambert Eaton myasthenic syndrome and neuromyotonia. Lisak will describe the immunology of multiple sclerosis and the experimental model EAE, in light of new developments in our understanding of the immune system and of the myelin structure and antigens. Weiner will describe current immunosuppressive treatments and possible future immunomodulation treatment strategies with antigenic and non-antigenic specific therapies including cytokines, monoclonal antibodies, peptides, $\mathrm{T}$-cell or $\mathrm{T}$-cell receptor vaccination, and oral tolarization to neural antigens.

S22.

Epilepsy Update

T.A. PEDLEY (Co-chair) (U.S.A.); E.H. REYNOLDS (Co-chair) (U.K.); U. HEINEMANN (Germany); B. SADZOT (Belgium); D. CHADWICK (U.K.); A. RICHENS (U.K.) and A. OLIVIER (Canada).

This symposium, organized by the International League Against Epilepsy, will provide critical reviews of selected clinical topics in contemporary epileptology. Dr. Heinemann will summarize new knowledge about basic mechanisms of epileptogenesis, including the imporatnce of specific ion channels and excitatory neurotransmitters which have implications for new antiepileptic drug development. Dr. Sadzot will describe biochemical studies of epileptogenic brain tissue using positron emission tomography (PET). Dr. Chadwick will review current factors and criteria, based upon recent prospective studies, that can be used to help determine when to initiate antiepileptic drug therapy and when to consider drug withdrawal. Dr. Richens will give an overview of new antiepileptic drugs, including comparisons with existing agents and a perspective on their anticipated place in managing patients with epilepsy. Dr. Olivier will conclude by describing the indications for, and timing of, surgical therapy. The symposium will include a panel discussion and question and answer period. 
S23.

\section{Mitochondrial Encephalomyopathies}

J.A. MORGAN-HUGHES (Co-chair) (U.K.); E. SATOYOSHI (Co-chair) (Japan); S. DiMAURO (U.S.A.); E. SHOUBRIDGE (Canada); D. WALLACE (U.S.A.); S. OHTA (Japan) and G. ATTARDI (U.S.A.).

In recent years, it has become evident that most mitochondrial cncephalomyopathies are associated with heteroplasmic mutations of milochondrial DNA (miDNA) usually involving single or multiple deletions, duplications or base substitutions in transfer RNA genes. While a few of these mutations appear to be relatively disease specific with only limited overlap, the majortiy also occur in other clinical phenotypes e.g., the MELAS mutation in matemally inherited diabetes (MDM) which may not directly involve the brain. The pathogenetic mechanisms of these disease mutations and how they relate to the different clinical and biochemical phenotypes will be the main themes of this Symposium. After an introductory overview by Morgan-Hughes, DịMauro will describe new methods for correlating the genetic, molecular and enzymatic defects at a cellular level. Shoubridge will discuss complementation and segregation of mutant mIDNAs and their thresholds for disease expression. Wallace will revicw the genetics of Leber's disease and MDM and the putative role of mtDNA mutations in neurodegenerative diseascs and in ageing. Ohta will describe the use of cellular models to study the effects of mutant mtDNAs on mt protein synthesis and respiration. Attardi will present new data on the complementation and segregation behaviour of disease mutations in cybrids and will review potential strategies for gene therapy.

\section{S24.}

The Impact of Economic Change on Clinical Neurology and Research

D. PURPURA (Co-chair) (U.S.A.); LORD WALTON (Co-chair) (U.K.); A. HOPKINS (U.K.); R. JOYNT (U.S.A.); I. KANAZAWA (Japan) and F. GERSTENBRAND (Austria).

Rising health care costs and barriers to access are shearing forces that have energized a 'Healthquake' whose temblors are being felt throughout the world. Neurology and Neuroscience research are at risk of being trapped in its rubble. Charles Dickens said it in the first twelve words of Tale of Two Cities: "It was the best of times, it was the worst of times ..." At no time in history have the opportunities for alleviating some of the most debilitating disorders of the human condition been so realizable. And at no time has the potential for violation of such expectations been so threatening. Economic factors will determine how various governments respond to their indigenous Healthquakes. This Symposium will explore the magnitude of the Healthquakes in different countries and the responses anticipated in relation to the teaching and practice of Neurology and Neuroscience research. The study of the brain in health and disease represents one of the noblest of human pursuits. The ediface of knowledge pertaining to disorders of the neuron system has been one of the crowning achievements of medical science. Unless its economic foundation is secured its future is in doubt. Congress attendees would be well advised to participate in this Symposium. If not now, when?

\section{THURSDAY}

\author{
S25.
}

Fulton Symposium: Growth Factors and the Nervous System

V. SORIANO (Co-chair) (Uruguay); E. SHOOTER (Co-chair) (U.S.A.); G. LANDRETH (U.S.A.); F. HEFTI (U.S.A.); H. THOENEN (Germany); R. LINDSAY (U.S.A.); S. VARON (U.S.A.) and R. LEVI-MONTALCINI (Italy).

The story of the discovery of nerve growth factor (NGF) is widely known. Equally well known is the impact of this discovery on several decades of developmental neurobiology. In presenting this tribute to Rita Levi-Montalcini the Fulton Symposium offers a glimpse of how this extraordinary field has developed in recent years. Three new members have been added to the NGF family, brain derived neurotrophic factor, neurotrophin -3 and neurotrophin $-4 / 5$. Their distributions and pattems of retrograde transport reveal specific but overlapping activities on both PNS and CNS neurons. Three tsk receptors, with neurotrophin activatible tyrosine kinase domains, mediate the biological activities of the neurotrophins with high but not absolute specificity while the role of the common neurotrophin receptor, $\mathrm{p} 75$, in modifying neurotrophin binding to the trks, either directly or through the signal transduction pathways, remains unclear. The ability of the neurotrophins to rescue injured or degenerating neurons offers potential therapeutic approaches to neurodegenerative diseases and emphasizes the need to understand how neurotrophin synthesis is regulated in CNS neurons or in glia. Ciliary neurotrophic factor, although chemically and functionally distinct from the neurotrophins, being related to cytokines such as interleukin-6 and leukemia inhibitory factor, has found prominence because of its neurotrophic activities on motoneurons. The cytokine-like activities of CNTF and the appearance of neurotrophin receptors on cells of the immune and neuroendocrine systems suggest broader roles for the neurotrophins.

Special Presentation by R. Levi-Montalcini

The Roles of NGF in Autoimmune Processes

A major shift in the Nerve Growth Factor (NGF) studies has recently occurred with the realization that the spectrum of action of this protein molecule is not restricted, as previously conceived, to enhancing differentiative processes of two peripheral neuronal cell lines (the sensory and sympathetic neurons), but extends also to several other neuronal and non-neuronal cell types. The newly detected NGF-responsive cells belong to the hemopoietic-immune system, to the cholinergic system of the basal forebrain nuclei, and to other cell populations of the central nervous system involved in neuroendocrine functions. Additional investigation showed that NGF is synthesized in some hypothalamic nuclei, and its level in the bloodsteam of mice displaying aggressive behavior is markedly increased. These and previous findings support the hypothesis that this protein molecule may exert a modulatory role on neuroimmune-endocrine functions of vital importance in the regulation of homeostatic processes.

S26.

\section{Neuro-Imaging}

M. RAICHLE (Co-chair) (U.S.A.); F. GERSTENBRAND (Co-chair) (Austria); J. FOWLER (U.S.A.); R. TURNER (U.K.) and J. MAKELA (Finland).

Twenty years ago the modern era of brain imaging began with the introduction of $x$-ray computerized tomography. Since that time 
brain imaging has become an integral part of the management of patients with neurological disease. For the most part, the clinical imaging studies have provided unique information about the anatomy of diseases of the human brain. However, as these techniques have developed and expanded much more information about the function of the human brain has become available. As a result scientists have begun to use these techniques to answer important questions about brain function, even normal brain function. This symposium is designed to acquaint neurological clinicians and scientists with the rapid advances that are currently being made with modem imaging techniques in the study of the human brain. Presentations will focus on the use of positron emission tomography (PET) for the study of brain pharmacology including the effects of drugs (Dr. Fowler) as well as normal function during learning, speaking, reading and remembering (Dr. Raichle); the use of magnetic resonance imaging (MRI) to study similar moment to moment changes in brain function using changes in intrinsic signals within the brain (Dr. Tumer); and, the use of a new type of non-invasive brain electrical recording, magnetoencephalography (MEG) (Dr. Makela) which offers the prospect of real time maps of brain function.

\section{S27.}

\section{Disorders of the Autonomic Nervous System}

C.J. MATHIAS (Co-chair) (U.K.); R. BANNISTER (Co-chair) (U.K.); P. LOW (U.S.A.); G. BURNSTOCK (U.K.); J. McLEOD (Australia); A. FERNANDEZ-KREKELER (Paraquay) and $R$. POLINSKY (U.S.A.).

This symposium will focus on currently important areas concerning the scientific basis, investigation and management of autonomic dysfunction in major neurological and medical disorders. The symposium will be chaired by Professor Mathias and Sir Roger Bannister. Professor Low will begin with the clinical and laboratory assessment of autonomic function. This will be followed by a stateof the-art scientific overview by Professor Burnstock on novel neurotransmitters and their implications in autonomic function. Professor McLeod will cover the peripheral autonomic neuropathies including newer syndromes such as dopamine beta-hydroxylase deficiency. Dr. Fernandez-Krekeler will deal with the pathophysiological and immunological basis of autonomic neuropathy in Chagas' disease along with aspects of management. The symposium will end with Dr. Polinsky and Professor Mathias discussing the treatment of autonomic dysfunction in neurodegenerative disorders, to include both the management of postural hypotension and also other widespread autonomic deficits which occur in these conditions.

Each lecture will provide an introduction to the subject, deal with the key features and combine the cutting edge of research with their implications for clinical practice.

S28.

\section{Neuro-Oncology}

J. POSNER (Co-chair) (U.S.A); J. HILDEBRAND (Co-chair) (Belgium); M. CHATEL (France); R. PATCHELL (U.S.A.) and Y. USHIO (Japan).

Neuro-oncology is a subspecialty of neurology which deals with the biology and management of primary central nervous system tumors, metastases to the nervous system and non-metastatic complications of systemic cancer that affect the central or peripheral nervous system. This symposium discusses new developments in the biology of brain tumors (Dr. Chatel), the current status and future directions in the clinical management of brain tumors (Dr. Hildebrand), the diagnosis and management of metastatic brain tumors (Dr. Patchell), the diagnosis and management of leptomeningeal tumors whether originating from systemic cancer or primary brain tumors (Dr. Ushio) and new developments in the biology of paraneoplastic syndromes with emphasis on the molecular biology of "onconeural" antigens (Dr. Posner).

\section{S29.}

\section{Presidential Symposium: Stroke 1993}

V. HACHINSKI (Co-chair) (Canada); J. TOOLE (Co-chair) (U.S.A.); R. BONITA (New Zealand); P.A. WOLF (U.S.A.); J.-M. ORGOGOZO (France); M.L. DYKEN (U.S.A.); J. VAN GIJN (The Netherlands); P. SANDERCOCK (U.K.) and H.J.M. BARNETT (Canada).

Seven experts in stroke epidemiology prevention and treatment will examine the fast-moving and controversial aspects of this field. The reasons behind the decline in stroke mortality will be examined critically. The growing evidence for the necessity to identify a risk profile and the effect of altering it will be reviewed. The controversy about the best type and dose of platelet-inhibitor will be aired. The potential role of anti-thrombotics in the acute phase of ischemic stroke will be considered. Finally the present state of knowledge of the use of surgery in preventing ischemic stroke will be summarized.

\section{S30.}

\section{Cognitive Neurology}

A. KERTESZ (Co-chair) (Canada); G. GAINOTTI (Co-chair) (Italy); B. GORDON (U.S.A.); G. MICELI (Italy); A. DAMASIO (U.S.A.); K. HEILMAN (U.S.A.) and G. GOLDENBERG (Austria).

The symposium endeavours to present a balanced update. Gordon (Baltimore) will discuss a combination of cortical stimulation and functional activation studies of language cognition. Recent advances in this area include the specific nature of processing certain elements of language, and the structure of the cortical mosaic. Miceli (Rome) will present the modern approach to the functional organization and anatomoclinical correlates of the lexical-semantic system. Damasio (Iowa) will use visual cognition as an example to highlight certain concepts of brain organization and function. Heilman (Gainesville) will deal with spatial representation and neglect in the context of responding to external stimuli in the space surrounding us in three-dimensions. Goldenberg (Vienna) explores the fractionation of memory compartments, the difference between procedural and semantic memory, category-specific, and modality specific memory storage. At the conclusion, questions arising from the presentation and generated by the audience pertaining to behavioural neurology and higher cortical function will be discussed by the panel of participants.

S31.

\section{Gene Therapy in Neuromuscular Disease}

R. WORTON (Co-chair) (Canada); LORD WALTON (Co-chair) (U.K.); F. GROS (France); I. VERMA (U.S.A.); M. COTTEN (Austria) and P. BAIRD (Canada).

Experimental gene therapy, for years thought of in association with the hematopoietic system, is beginning to be considered for diseases of the neuromuscular system. Genes responsible for 
Duchenne muscular dystrophy and myotonic dystrophy have been identified and those responsible for other neuromuscular disorders are not far behind. The technology to carry out gene therapy is advancing rapidly but is it realistic for the forseeable future? François Gros, former head of the Institute Pasteur will set the stage for the discussion by providing a simple overview of the prospects for gene therapy in neuromuscular disease. Inder Verma will discuss the introduction of foreign genes (such as factor IX) into muscle where the protein product is made and exported to the bloodstream. Ronald Worton will focus the discussion on artificial gene constructs encoding dystrophin for gene therapy in Duchenne muscular dystrophy and Matt Cotten will describe their new and exciting work on targeting gene constructs to muscle and other tissues through receptor-mediated endocytosis. Gene therapy has generated considerable public concern, some well-founded but most related to fear based on ignorance of the facts. Patricia Baird, Head of Canada's Royal Commission on New Reproductive Technologies, will discuss some of the social, ethical and legal issues identified with gene therapy. Lord John Walton, President of the World Federation of Neurology will offer concluding remarks to round out a symposium designed to educate the practising neurologist about this potentially new form of treatment.

\section{S32.}

\section{Preparing Neurologists for the 21st Century}

J.B. MARTIN (Co-chair) (U.S.A.); T.J. MURRAY (Co-chair) (Canada); M.R. HAYDEN (Canada); S.L. HAUSER (U.S.A.); R.S.J. FRACKOWIAK (U.K.) and R.C. GRIGGS (U.S.A.).

The dynamic changes that have occurred in understanding the pathogenesis of neurologic disorders and the implications that these discoverics have for new treatments and for presymptomatic diagnosis of inherited diseases are the subject of this symposium. It has become increasingly difficult for a clinical neurologist to keep abreast of these discoveries. The purpose of this symposium is to revicw the emerging impacts of molecular genetics on the diagnosis and presymptomatic testing of inherited neurologic diseases and to review the new approaches that are being used to target specific immunotherapies for the prevention and treatment of multiple sclerosis and other autoimmune disorders. In addition, the rapid progress that is being made in using techniques of positron emission tomography, magnetic resonance imaging, and magnetic resonance spectroscopy for mapping the human brain will be discussed. Finally, the impact of molccular diagnostics and molecular neuroscience on the management of patients with neuromuscular disorders will be presented.

\section{FRIDAY}

T4.

\section{Environmental Neurology}

P.S. SPENCER (Co-chair) (U.S.A.); N.H. WADIA (Co-chair) (India); F. HE (China); A. ARREGUI (Peru); R. HAIMANOT (Ethiopia); H. RWIZA (Tanzania); H. ROSLING (Sweden); M. LOTTI (Italy); A. PORTERA-SANCHEZ (Spain); J. HUGON (France) and A. LUDOLPH (Germany).

The session examines a spectrum of neurological disorders associated with human exposure to environmental factors. Some $\alpha c$ in Nature, others have been introduced through human activity; some are associated with acute disorders, others are linked with diseases that surface weeks, months or perhaps even years after exposure. Most exploit directly the inherent vulnerabilities of the nervous system, such as the absolute dependence on a continuous supply of energy. Four speakers will address this theme by exploring the disparate neurological outcome associated with acute and chronic disruption of energy transformation from agents present in air and food. This experience will be used to examine the relationship between energy disruption, excitatory amino acids, and motor neuron disordérs, and the possible causes of the current epidemic of opticotomyeloneuropathy in Cuba which, through July 1993, reportedly has affected over 40,000 individuals. The relationship between the unsolved Spanish Toxic Oil Syndrome and the Eosinophilia-Myalgia Syndrome will be addressed, and mechanisms underlying the neurotoxic actions of organophosphate pesticides presented.

\section{S33.}

\section{Parkinsonism}

M.D. YAHR (Co-chair) (U.S.A.); H. NARABAYASHI (Co-chair) (Japan); Y. MIZUNO (Japan); A.H.V. SCHAPIRA (U.K.); D. BROOKS (U.K.); D. CALNE (Canada); U. RINNE (Finland) and Y. AGID (France).

There is growing interest in the role of abnormalities of mitochondrial function in the pathogenesis of Parkinson's disease. PET has made major contributions to understanding the pathophysiology of the basal ganglia, and to the early detection of Parkinson's disease. The management of Parkinson's disease remains a matter of debate and controversy. Speakers in this symposium have been chosen to air these issues.

\section{S34.}

\section{Ethics in Neurology: Cross-Cultural Considerations}

M.M. COHEN (Co-chair) (U.S.A.); B. BARAC (Co-chair) (Croatia); D. VIDAVER COHEN (U.S.A.); B. SINGHAL (India); Z.-P. QU (China); M. BEN HAMIDA (Tunisia) and J. BERNAT (U.S.A.).

This program will examine ethical constructs in different cultures pertaining to two major interrelated problems related to practice and research in Neurology, 1) Patients' rights and physician responsibility, and 2) Clinical Research. Informed consent will be considered for both issues. The initial presentation will be concerned with the role of cultural views in determining ethical positions. North American (Judeo-Christian) North African (Muslim), Indian (Hindu) and Chinese ethical views will then be considered. Although informed consent is generally required there is variation in the responsibility for that consent in different societies. Finally the relation of these ethical considerations to the law in a multi-ethnic society will be considered.

\section{S35.}

\section{Intensive Care of the Neurologic Patient}

A.H. ROPPER (Co-chair) (U.S.A.); R.E.P. SICA (Co-chair) (Argentina); W. HACKE (Germany); D.F. HANLEY (U.S.A.); J. NEWSOM-DAVIS (U.K) and C.F. BOLTON (Canada).

The modern neurologist who cares for patients with critical medical and neurological illnesses requires several new skills and knowledge of recently described conditions. As an overview of this field, the Intensive Care Symposium will review acute stroke therapy and its complications, systemic medical complications of neurologic 
illness, particularly fluid and electrolyte derangements, and several topics relating to severe neuromuscular disease including respiratory failure, critical illness polyneuropathy, and treatment of GuillainBarré syndrome and myasthenia gravis.

\section{S36.}

\section{What's New in Multiple Sclerosis?}

W.I. McDONALD (Co-chair) (U.K.); C. FIESCHI (Co-chair) (Italy); G. EBERS (Canada); A. THOMPSON (U.K); D.A. COMPSTON (U.K); S. RAO (U.S.A.); R. HOHLFELD (Germany); K. JOHNSON (U.S.A.) and D.W. PATY (Canada).

The symposium will address five quesitons about multiple sclerosis which are of much current interest. They concern epidemiology (and in particular whether the frequency of multiple sclerosis is increasing); the pathogenesis (and in particular the nature of repair processes and the mechanism of irrecoverable deficit); whether cognitive abnormalities make a significant contribution to disability; and how best the disease should be treated with a view to modifying its course. The role of beta interferon and other possible future strategies will be discussed.

\section{S37.}

\section{Recovery After CNS Injury}

D.L. MCLELLAN (Co-chair) (U.K.); M.P. BARNES (Co-chair) (U.K); D. STEIN (U.S.A.); D. SMITH (Australia); P. BACH-Y-RITA (U.S.A.); P. PINELLI (Italy) and B. WILSON (U.S.A.).

The symposium will discuss the relationship between the physical events occurring in the brain during recovery from injury and the changes in function that are observed clinically. The aim is to use current knowledge from basic science and clinical science to illuminate each other and to suggest hypotheses that can be tested by further experimental work in both fields.

Context and environment play an important role in determining function and the outcome of brain damage on cerebral functions. The eventual severity and distribution of neuronal damage reflects a complex sequence of events that are potentially susceptible to manipulation at different points in time after the injury. Clinical observations have documented a complex sequence of events during recovery but the clinical evidence that the early phases of brain recovery can be altered by therapy is suggestive rather than conclusive. By contrast, there is good evidence that complications that are secondary to immobility, spasticity or altered caloric requirements can be ameliorated.

Clinical recovery in function has been shown conclusively to continue for at least five years after injury. The changes occurning in a group of patients between 11 and 33 months after traumatic brain injury will be presented in detail. The effects of treatment in these subjects and a further group with hemiplegia suggest that CNS function can be both opposed and enhanced by treatment. Cognitive improvements have also been demonstrated to occur in a group of subjects followed up for many years after diffuse traumatic injury.

Late changes in neural activity following neonatal and adult brain and peripheral nerve lesions have been demonstrated by changes in functional representation and by metabolic (PET scan) studies. Synaptic and non-synaptic diffusion neurotransmission (NDN) mechanisms are apparently involved in the functional reorganization. Brain connectivity changes underlying late recovery are of considerable interest for the development of therapies to improve the outcome of rehabilitation.

S38.

\section{Movement Disorders}

W. OERTEL (Co-chair) (Germany); C.D. MARSDEN (Co-chair) (U.K); S. FAHN (U.S.A.); A. KORCZYN (Israel); H. SHIBASAKI (Japan); P. THOMPSON (U.K.) and O. HORNYKIEWICZ (Austria).

This symposium will address topics other than parkinsonism that are now considered to be part of the growing family of "Movement Disorders". In addition to such traditional topics as dystonia and tic, the symposium includes reviews on myoclonus and "the stiff person syndrome", which are less frequently considered in a setting that has previously focused attention on pathology involving the extrapyramidal system. In this way, full recognition will be given to the expanding area of responsibility for the steadily increasing number of Movement Disorder Clinics that are emerging throughout the world. 